\title{
MEMÓRIA FOTOGRÁFICA DE PESQUISA DE CAMPO ANTROPOLÓGICA ENTRE OS MACUXI DA ÁREA RAPOSA-SERRA DO SOL NOS ANOS 1990.
}

\author{
Geraldo Barboza de Oliveira Junior ${ }^{1}$
}

Os Macuxi foram minha primeira experiência etnográfica com povos indígenas. Nos anos 1990 fui aprovado em um concurso para professor de Universidade federal de Roraima. Nesta oportunidade fui, também, convidado por amigos indígenas (que conhecia da época que tinha sido repórter em jornais de Roraima) a visitar a maloca da Raposa, considerada a capital da Raposa-Serra do Sol. Nesta ocasião, fui recebido pelo Tuxaua (in memoria) Caetano Raposo e sua família. Os momentos vividos em companhia de minha filha (na época com 03 anos de idade) foram divididos com seus familiares.

A experiência que obtive com o convívio com os Macuxi, foi além da necessidade etnográfica. Estabeleceu-se um espaço de convivência e admiração pelo povo Macuxi. A visita inicial cedeu espaço a momentos mais ricos. Conseguimos, via UFRR, implantar um curso de Pedagogia na Maloca da Raposa exclusivo para alunos indígenas. Oportunamente, fiz da Área Indígena Raposa-Serra do Sol meu campo de pesquisa para o mestrado. Tive êxito. Cursei e defendi dissertação sobre os Macuxi e sua relação com as políticas de desenvolvimento na região.

São estes momentos que, passados mais de 20 anos, divido agora através de parte da memória visual desta experiência. É a antropologia visual, não apenas coadjuvante no processo de construção etnográfica. Em algumas situações, as fotos falam por si. De acordo com Barthes (1984:49):

Como a Fotografia é contingência pura e só pode ser isso (é sempre alguma coisa que é representada) - ao contrário do texto que, pela ação repentina de uma única palavra, pode fazer uma frase passar da descrição à reflexão - ela fornece de imediato esses 'detalhes' que constituem o próprio material do saber etnológico.

As fotos abaixo, tiradas nos anos 1990 durante o trabalho de campo na Maloca da Raposa, são parte desta memória acadêmica e afetiva. As fotos foram "devolvidas" à comunidade em dois momentos distintos: logo após os trabalhos de campo e, novamente, no ano de 2016 (para os filhos-já adultos- de Caetano Raposo).

Neste trabalho, oriento-me pelo referencial proposto por Achutti (1997:12-13) que cita:

\footnotetext{
${ }^{1}$ Antropólogo Mestre. Membro do IDEA-RN: Instituto de Desenvolvimento, Planejamento e Educação Ambiental.
} 
"Através de uma abordagem descritiva, em que a principal forma de narrar é o uso de imagens, através de um exercício de uma antropologia visual, utilizando a técnica fotográfica - uma fotoetnografia - busco investigar os elementos com os quais esta população constrói os traços de sua identidade...

(...)

...busco pensar e desenvolver a própria antropologia visual como linguagem como uma linguagem e um olhar, capaz de, no processo de conhecer, nos dar dados. Procuro, teoricamente, trabalhar a questão da imagem em seu potencial descritivo e suas históricas conexões com a antropologia

(....)

A proposta aqui é a do emprego da antropologia visual enquanto um recurso narrativo autônomo na função de convergir significações e informações a respeito de uma dada situação social."

As respostas, em ambos, os momentos foram de gratidão e reconhecimento de uma importância histórica dos fatos relembrados. $\mathrm{Na}$ atualidade, as redes sociais dão maior visibilidade aos dados mostrados. As fotos se transformam em histórias e garantidoras de uma memória que legitima uma identidade. Os Macuxi da Raposa-Serra do Sol no fim do Século XX.

$\mathrm{Na}$ atualidade, os Macuxi mantem sua relação com a sociedade local (e externa), ao mesmo tempo, intensa e sem comprometer seus valores culturais. Se afirmam como indígenas, rejeitando o termo Caboclo, falam e escrevem em Macuxi, promovem festivais culturais, ressaltando sua gastronomia, sua religiosidade e a sua relação com o meio ambiente como elementos definidores de sua identidade étnica.

Atualmente, os jovens usam (bastante) os meios de comunicação e redes sociais; dispensando, assim, novos pesquisadores externos à sua cultura. Estas fotos, então, se prestam a preencher lacunas de um passado recente e; ao mesmo tempo, homenagear o Tuxaua Caetano Raposo.

\section{REFERÊNCIAS}

BARTHES, Roland. A Câmara Clara. Rio de Janeiro: Nova Fronteira, 1984

ACHUTTI, Luiz Eduardo Robinson. Fotoetnografia: um estudo de antropologia visual sobre cotidiano, lixo e trabalho. Porto Alegre: Tomo Editorial: Palmarinca, 1997. 

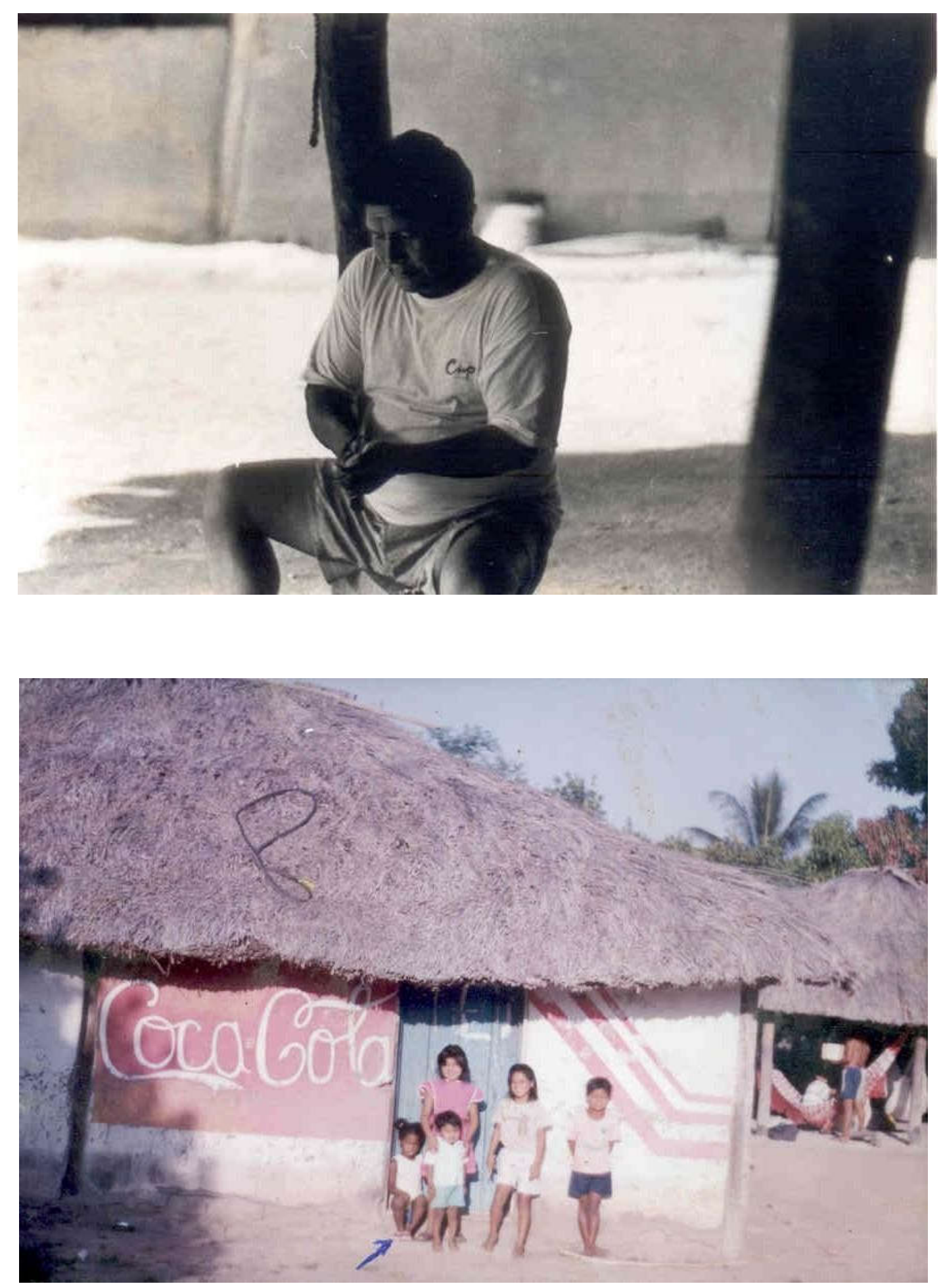


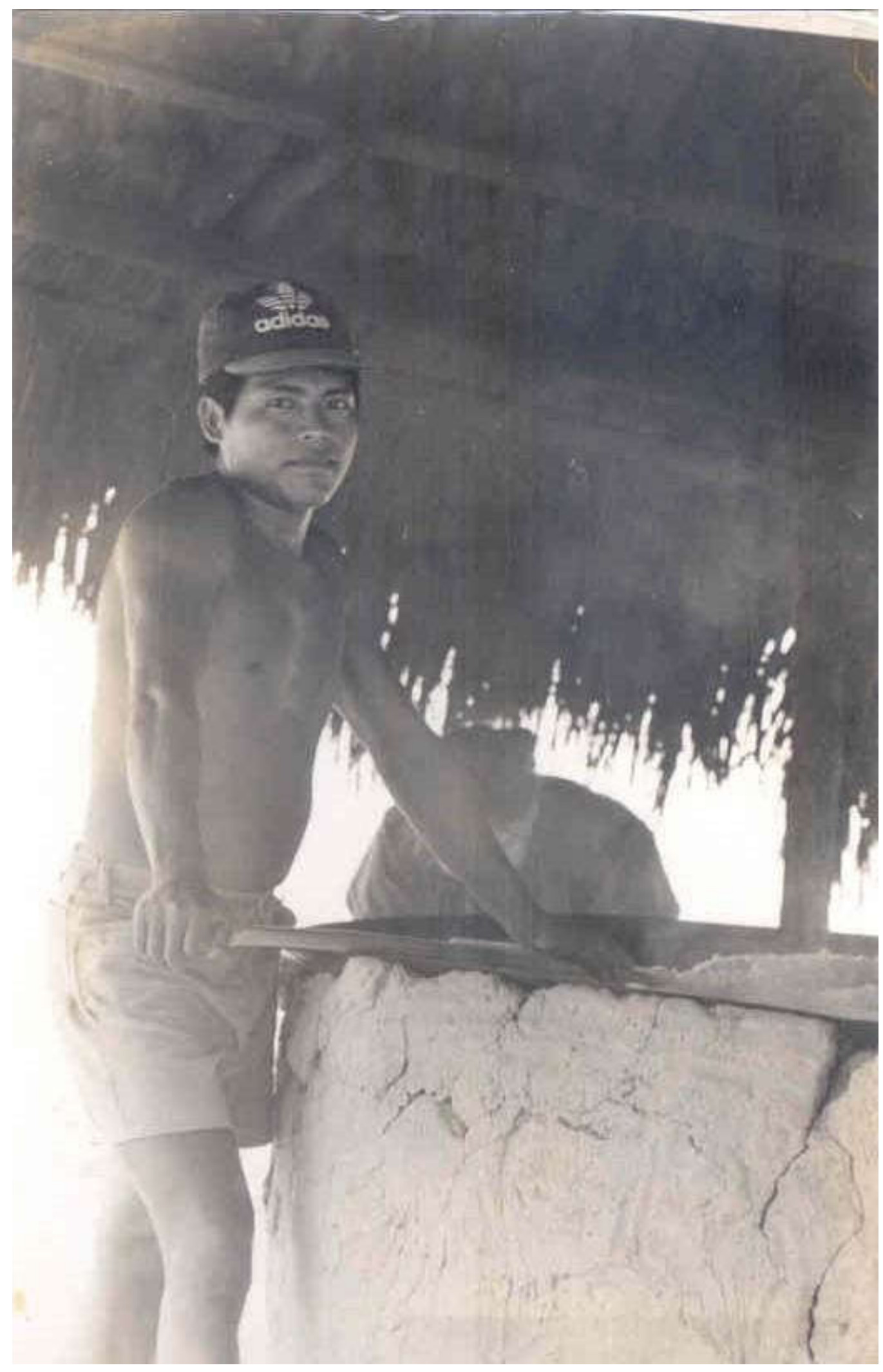

Nova Revista Amazônica - ANO IV - Volume 3 - DEZEMBRO 2016 - ISSN: 2318-1346 

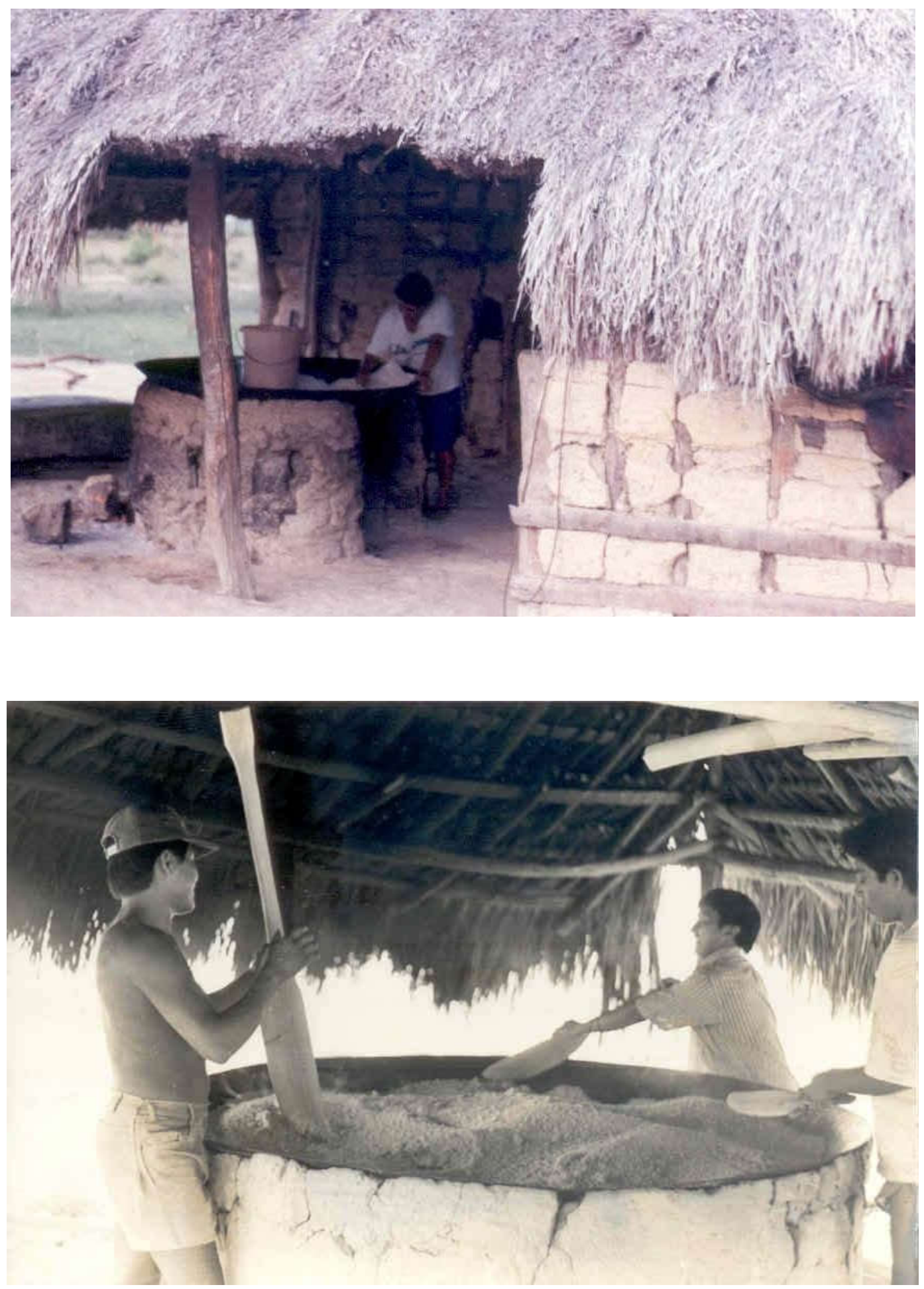

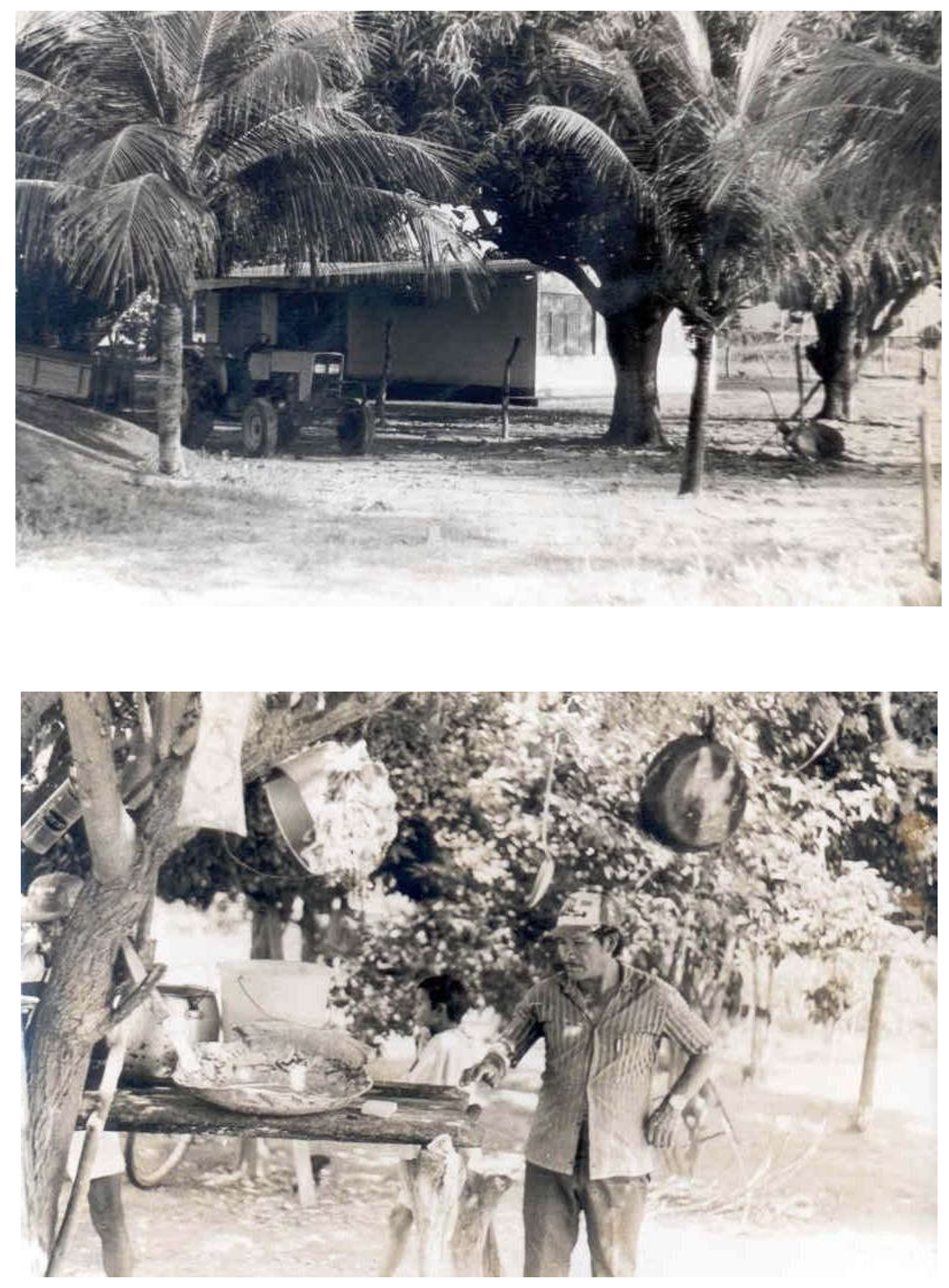

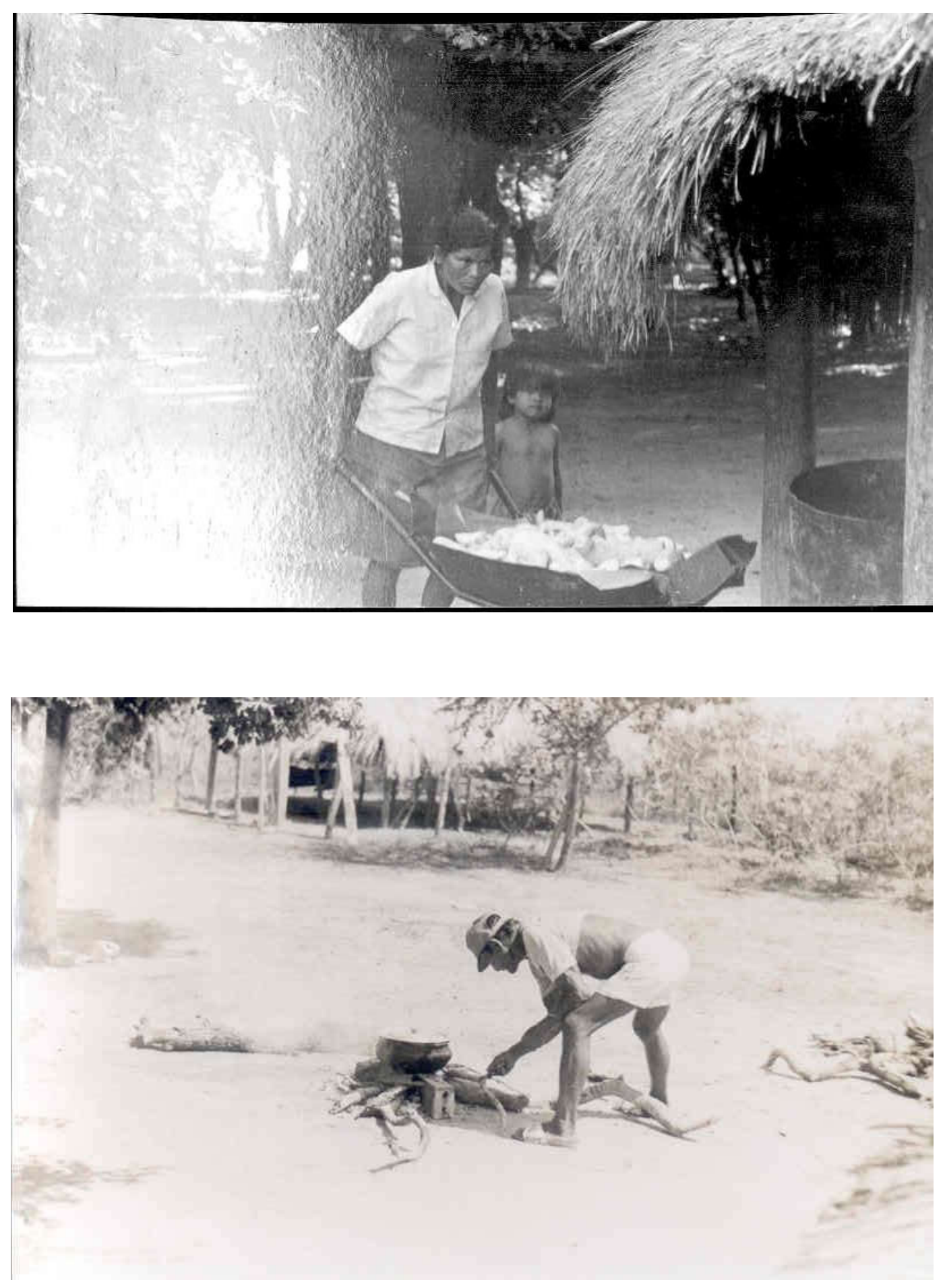